\title{
Reflux of duodenal contents in the pathogenesis of pancreatitis
}

\author{
A. D. McCUTCHEON \\ From the Baker Medical Research Institute, Melbourne, Australia ${ }^{1}$
}

EDITORIAL SYNOPSIS It is concluded from these studies that reflux of duodenal contents is likely to be the cause of most cases of acute pancreatitis.

Two ideas have dominated the subject of the aetiology of pancreatitis since Opie's classical paper in 1901: the reflux of bile into the pancreatic duct and obstruction of the pancreatic duct. The biliary reflux theory also depends upon obstruction, either organic or spasm, at the termination of the pancreatic and common bile ducts with the formation of a common channel along which bile may flow. Serious objections have been raised to both these theories, however, and in a recent study (McCutcheon, 1962) it was shown that the anatomy of the ducts in fatal cases of pancreatitis favoured reflux of duodenal contents rather than reflux of bile.

\section{EXPERIMENTAL EVIDENCE}

Acute haemorrhagic pancreatitis may be produced in dogs by creating a blind duodenal loop into which the pancreatic ducts drain but from which bile has been excluded (Pfeffer, Stasior, and Hinton, 1957). Its macroscopic and microscopic features are strikingly similar to those found in acute haemorrhagic pancreatitis in man. We have shown (McCutcheon and Race, 1962) that this form of experimental pancreatitis is produced by reflux of duodenal contents into the pancreatic duct since it can be prevented from developing by simple ligation of the pancreatic ducts (Fig. 1 and 2). Particles of barium sulphate introduced into the blind loop at the time of operation can be found later inside the main pancreatic duct.

The demonstration that increased intraduodenal pressure may force fluid past a normal pancreatic duct papilla in vivo is in contrast to the experiments of Archibald (1919) who found it impossible to force fluid from the duodenum into either the common bile duct or pancreatic duct after one

${ }^{1}$ Postal address: Commercial Road, Prahran S1, Victoria, Australia. hour's sustained pressure. He used post-mortem material, however, in which the dynamic processes of contraction and relaxation were absent.

More significant is the fact that acute pancreatitis may complicate a Billroth II partial gastrectomy in man when there is obstruction of the afferent loop (Perman, 1935; Wallensten, 1958) and here the conditions are almost identical with those found in the experimental blind loop in the dog. It is difficult to avoid the conclusion that the same mechanism is responsible for pancreatitis in both instances.

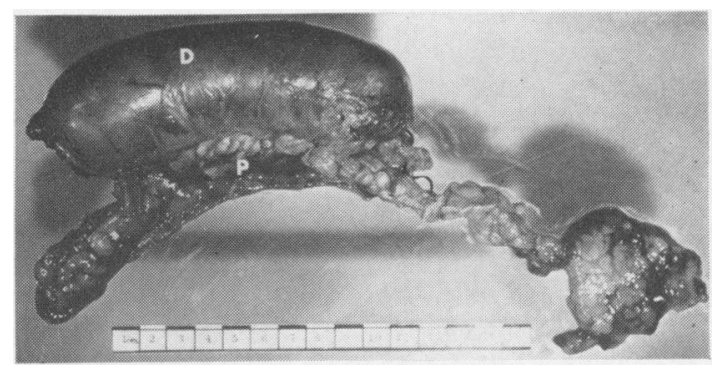

FiG. 1. Blind duodenal loop (D) attached to haemorrhagic pancreas $(P)$.

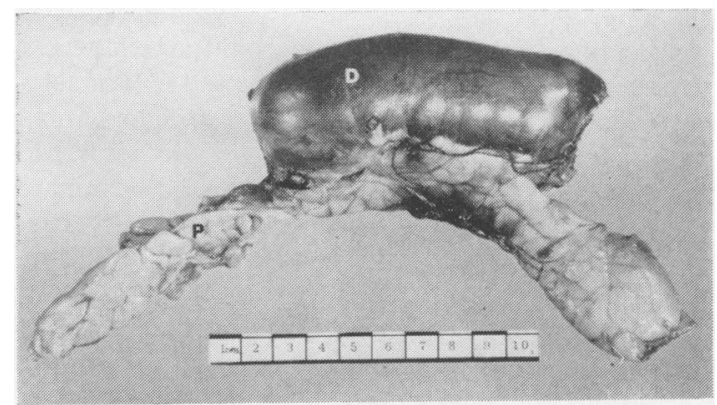

FIG. 2. Blind duodenal loop $(D)$ with ligated pancreatic ducts. Normal white pancreas $(P)$. 




FIG. 3. Transverse section of normal pancreatic duct papilla in the dog showing the tortuous, maze-like appearance of the lumen due to the numerous fine mucosal 'valvules'. Low power.

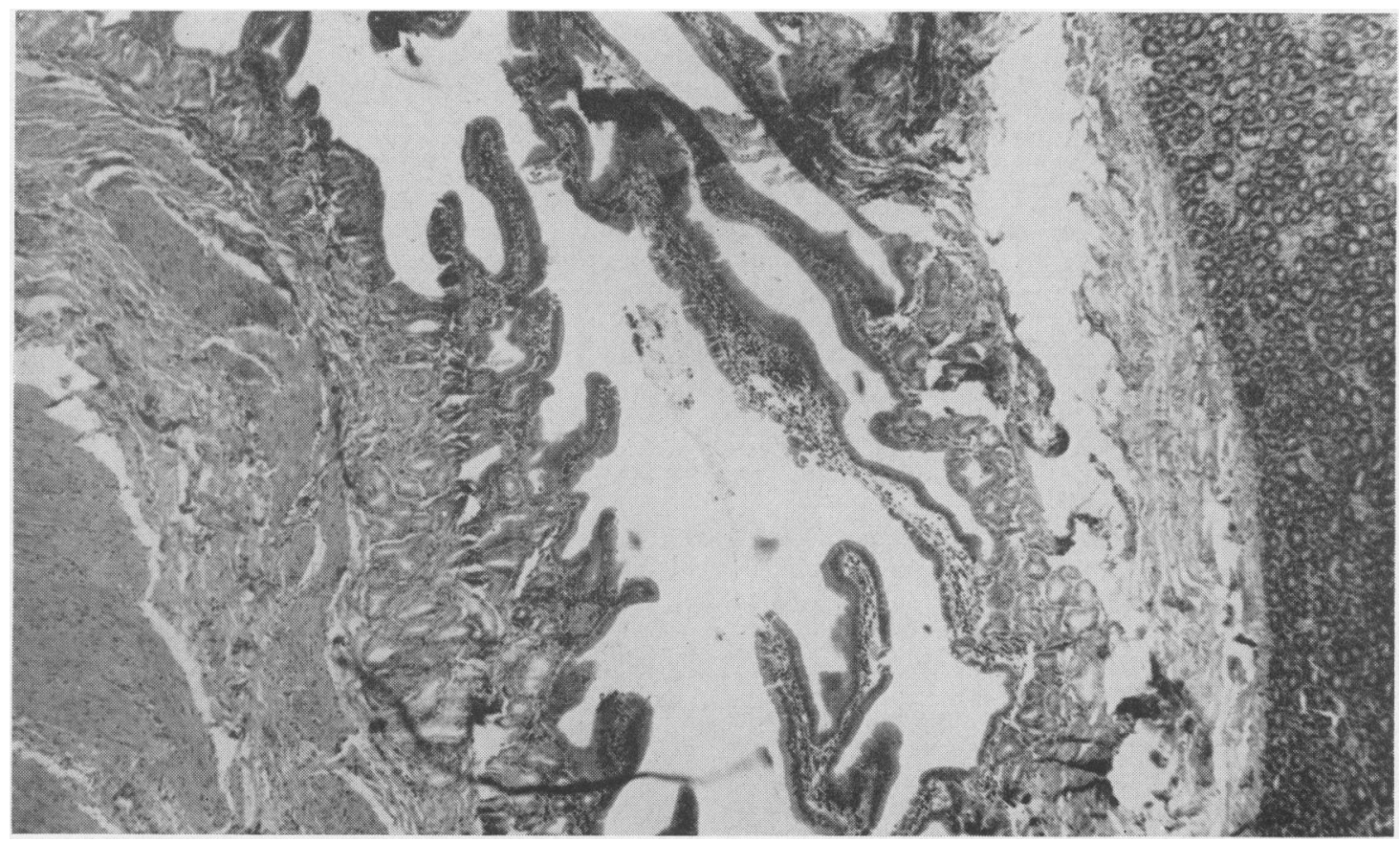

FIG. 4. The appearance of the pancreatic duct papilla after papillectomy (see text). Many of the mucosal fronds have been removed and the duct lumen is apparent, but other mucosal 'valvules' of varying length are seen projecting into the lumen. Low power. 
As a result of the blind loop experiments in which the pancreatic duct papilla was normal, it was suggested that 'pancreatitis may be produced by much smaller pressure changes in the duodenum provided the duct papilla is damaged or incompetent' (McCutcheon and Race, 1962). The normal papillary openings of the pancreatic and common bile ducts in man and dogs are lined by delicate mucosal folds or valvules (Fig. 3). The function attributed to these folds is that of prevention of regurgitation of duodenal contents (Dardinski, 1935; Schwegler and Boyden, 1937; Sterling, 1949; Cross, 1956). The mechanical effect of damage to these valvules with regard to duodenal reflux was tested in the following way, after the method of Newman, Weinberg, Newman, and Northup (1958).

The duodenum and pancreas were removed from dogs immediately after they had been sacrificed. In the dog the minor pancreatic duct opens beside the common bile duct. The main pancreatic duct enters the duodenum separately, 2 to $3 \mathrm{~cm}$. below the common bile duct papilla. All three ducts were identified and cut across so as to leave a short length of duct attached to the outer surface of the duodenum. A glass cannula was introduced into one end of the duodenum and connected via a three-way tap to a mercury manometer and to a syringe. The other end of the duodenum was clamped.

The duodenum was filled with saline coloured with methylene blue until the intraduodenal pressure was equal to $30 \mathrm{~mm}$. of mercury. This pressure could be maintained for more than five minutes without any fluid escaping from the cut ends of the ducts. The duodenum was then opened by an incision opposite the papilla of the lower main pancreatic duct. By pressing on either side of the papilla with the open blades of a pair of scissors it could be made to stand out from the surrounding mucosa and excised. The aim was to remove the small mucosal portion of the duct papilla with its contained mucosal 'valvules' without damaging the main thickness of the bowel wall containing the muscle layers.

The duodenotomy incision was clamped and the intraduodenal pressure again raised to $30 \mathrm{~mm}$. of mercury. After a minute or two, blue solution began to ooze slowly from the cut end of the lower pancreatic duct, but not from the upper pancreatic duct or common bile duct whose common papilla had been left intact. The region of both duodenal papillae was removed, fixed and sectioned, and the normal papilla (Fig. 3) compared with the picture seen after papillectomy (Fig. 4), so that the degree of damage could be assessed. This procedure was repeated three times using different specimens of duodenum and results were the same on each occasion.

Finally, in one specimen the common bile duct papilla was excised as well as the main pancreatic duct papilla, and when the intraduodenal pressure was then raised to $30 \mathrm{~mm}$. of mercury, blue fluid was observed escaping from the cut end of the common bile duct as well as from the lower pancreatic duct.
COMMENT

These experiments, in contrast to those in vivo show that passive distension of the isolated duodenum does not result in reflux of duodenal contents through a normal duct papilla, but that reflux occurs readily at physiological pressures if the papillary mucosal folds are damaged. It is a reasonable supposition on mechanical grounds that atrophic changes in these mucosal 'valvules' in man would also allow reflux of duodenal contents into the ducts at low pressures, and that this would be a recurrent event. Unfortunately we are ignorant about the histology of the mucosal valvules in patients with pancreatitis, but such a mechanism could explain the frequent and disabling recurrences of pancreatitis which may occur with chronic alcoholism. Although this is highly speculative, the mechanical facts are plain and it may be possible to test this suggestion by the examination of fresh material obtained surgically from patients undergoing operation for chronic pancreatitis. Extensive post-mortem changes make necropsy material almost useless.

A new proteolytic enzyme inhibitor, Trasylol $^{1}$, is available which can be given safely intravenously to man and to animals and which has been used in the treatment of human pancreatitis (Forell, 1962). If a continuous intravenous infusion of this substance is given to a group of dogs with the Pfeffer blind duodenal loop (Fig. 5) it prevents the development of pancreatitis (McCutcheon and Race, 1963). This powerful protective action of Trasylol suggests that all the typical pathological features of haemorrhagic pancreatitis which normally follow the blind loop procedure and reflux of duodenal contents into the pancreatic duct are due to the action of active proteolytic enxymes.

Some authors have doubted whether these ${ }^{1}$ Farbenfabriken Bayer A. G. Leverkusen, Germany.

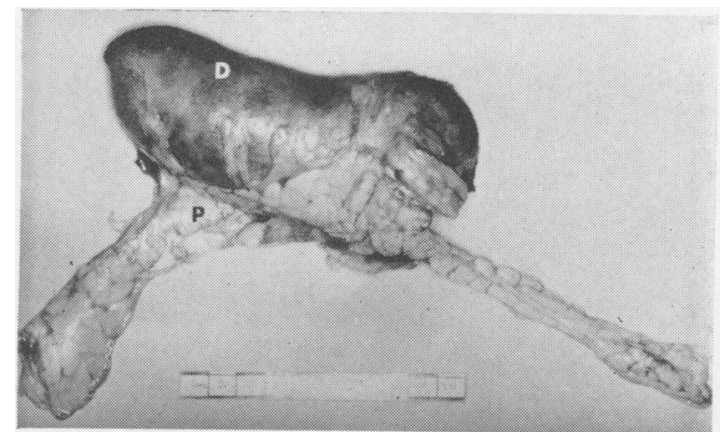

FIG. 5. Blind loop $(D)$ and attached normal pancreas $(P)$ in $a$ dog given a continuous intravenous infusion of Trasylol. 
enzymes play any part in the production of pancreatic necrosis because they do not digest healthy cells (Hosie and Ziffren, 1956; Reid, Paulette, Challis, and Hinton, 1958; Ferrini and Zito, 1961). The proteolytic enzymes are powerful blood-clotting substances, however (Ferguson, Wilson, Iatridis, Rierson, and Johnston, 1960), and one of them, elastase, may attack the elastic laminae of blood vessels (Probstein and Blumenthal, 1961). I believe that the initial site of action of the active enzymes is in small blood vessels where stasis and thromboses lead first to interstitial oedema and later to haemorrhage and infarction of pancreatic acini. The final pathological process is regarded as 'one of infarction and haemorrhage rather than autodigestion' (McCutcheon, 1962).

\section{RADIOLOGICAL EVIDENCE}

Reflux of duodenal contents into the pancreatic

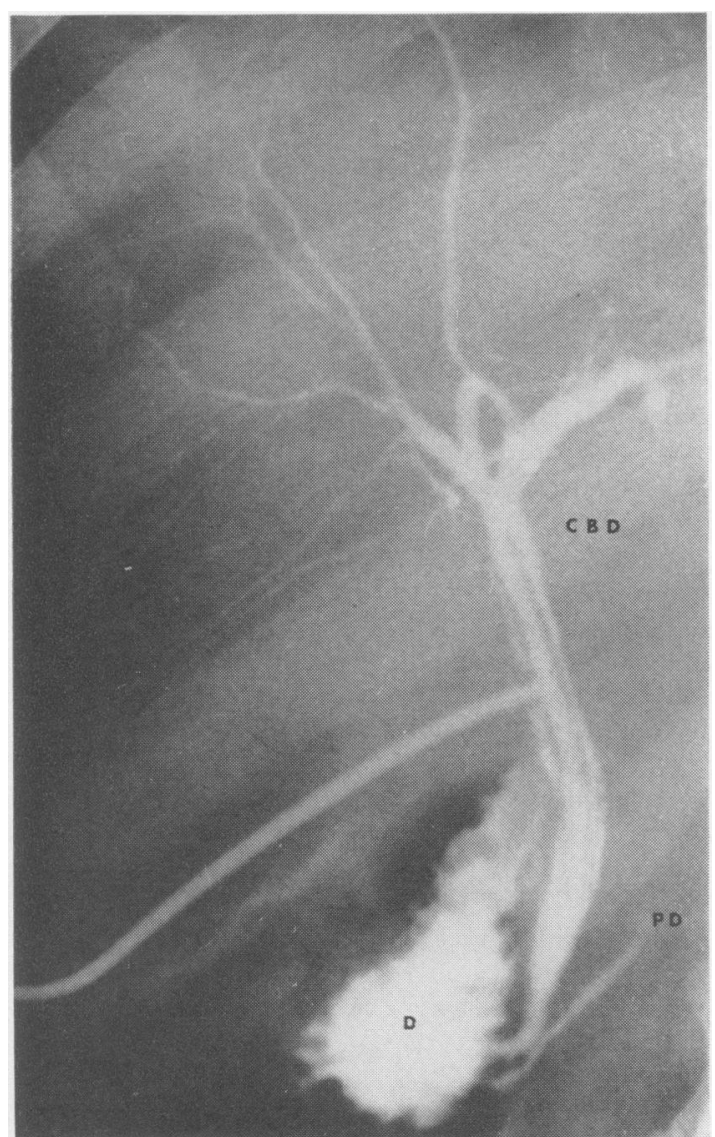

FIG. 6. Choledochogram showing separate openings of the pancreatic $(P D)$ and common bile ducts $(C B D)$ with 'duodenal reflux'. ( $D=$ contrast medium in duodenum.) duct may be demonstrated by the radiologist. Figure 6 shows a choledochogram done on a woman with a history of recurrent attacks of pain in the right hypochondrium, radiating to the back. At operation many small stones were found in the gall bladder. This choledochogram, performed postoperatively, shows widely separated openings of the pancreatic and common bile ducts with reflux of dye from the duodenum into the pancreatic duct.

Hicken and McAllister (1952) analysed 100 cases of cholelithiasis and choledocholithiasis in which the pancreatic duct was outlined during cholangiography. It united with the bile duct to form a common channel in only 30 cases; in 57 the ducts opened together into the duodenum through a shallow papilla and in $\mathbf{1 3}$ the common bile duct and pancreatic duct had completely separate orifices. Caroli, Porcher, Pequignot, and Delattre (1960), using a cineradiographic technique, showed that reflux of dye into the pancreatic duct occurred only during the phase of relaxation of the sphincter of Oddi and that where the ducts had separate openings contrast material entered the duodenum before passing along the pancreatic duct.

One may conclude that reflux of duodenal contents has been demonstrated beyond reasonable doubt in a proportion of patients with gall stones and it is of interest that there is a known association between gall stones and pancreatitis.

\section{DISCUSSION}

For many years the aetiology of pancreatitis has been a confused subject and this may well be due to the persistent belief in the theories of billary reflux and pancreatic duct obstruction. The emphasis on obstruction is probably a reflection of the surgical approach to pancreatitis, as most of the experimental work has been done by surgeons and most patients with pancreatitis are admitted to surgical wards. The very strong evidence against these theories was discussed recently and only the main points will be stated here (McCutcheon, 1962).

A common channel does not exist in many cases of pancreatitis (Mann and Giordano, 1923; Clark, 1942; Bartlett and Nardi, 1960; McCutcheon, 1962).

Papillary obstruction of either the pancreatic or common bile ducts is rarely found in acute pancreatitis; hence spasm of the sphincter of Oddi was invoked as the obstructing agent.

Tonic spasm of the sphincter of Oddi closes both ducts and prevents any sort of reflux (Judd, 1921; Hughes and Kernutt, 1954; Caroli et al., 1960).

Experimental obstruction of the pancreatic duct causes atrophy of acini, not pancreatitis (Wang, Wang, and Grossman, 1950; Becker and Schaefer, 1957). 
Bile does not activate pancreatic proteolytic enzymes (White and Magee, 1960) and diversion of bile into the pancreatic duct does not produce pancreatitis (Thal, Perry, and Egner, 1957).

Deliberate ligation of the pancreatic ducts in man does not cause pancreatitis even in patients with recurrent pancreatitis (Howard and Jordan, 1960).

There must be very few other theories in medicine which are still adhered to in the face of such evidence.

One of the earliest theories about the genesis of pancreatitis was concerned with reflux of duodenal contents into the pancreatic duct. It was discussed fully by Opie in 1901 and rejected on the grounds that 'it is well known that increased pressure within the duodenum does not force duodenal contents into the bile duct or into the pancreatic duct after death'. Archibald's experiments in 1919 supported this statement and since then the theory has been quietly and almost completely buried, although Dragstedt Haymond, and Ellis, in 1934, considered the arguments against reflux of duodenal contents causing pancreatitis, and at the same time cited some evidence in support of such reflux.

The experimental evidence outlined in this paper shows that the theory of reflux of duodenal contents was dismissed on inadequate grounds. From the evidence we may conclude:

1 Reflux of duodenal contents into the pancreatic duct is capable of producing all the characteristic features of acute haemorrhagic pancreatitis as a result of the action of proteolytic enzymes.

2 Reflux of duodenal contents into the pancreatic duct may occur under the following conditions:

(a) Normal intraduodenal pressure and relaxation of the sphincter of Oddi; this was demonstrated radiographically in a group of patients with gall stones, a disease which is commonly associated with pancreatitis.

(b) Increased intraduodenal pressure and a normal pancreatic duct papilla; this has been produced experimentally in dogs and spontaneously in man following Billroth II partial gastrectomy.

(c) Relatively low intraduodenal pressures and an abnormal pancreatic duct papilla where the mucosal folds at the orifice of the duct are deficient. This has only been demonstrated experimentally so far.

The theory of reflux of duodenal contents as the cause of most cases of pancreatitis does not conflict with known facts about the disease. It is compatible with the anatomical arrangements of the ducts found in patients with pancreatitis (McCutcheon, 1962), and provides a rational and simple explanation for the activation of pancreatic proteolytic enzymes and the subsequent pathological changes. By the known effects of fat and general anaesthetics in relaxing the sphincter of Oddi it can account for pancreatitis following fatty meals and following operations not related to the billiary system. In association with inadequate or atrophic papillary valvules it can explain chronic relapsing pancreatitis.

It is not necessary to postulate reflux of duodenal contents in all cases of pancreatitis. In pancreatitis complicating hyperparathyroidism there may be a more direct mechanism. I have suggested that the primary site of action of active proteolytic enzymes is on the smaller blood vessels in the interstitial tissue of the pancreas. There is considerable evidence that parathormone is capable of causing haemorrhages, thromboses, and small foci of necrosis in myocardium, kidneys, stomach, and skeletal muscles as well as in the pancreas (Hueper, 1927; McJunkin, Tweedy, and Breuhaus, 1932; Thomas, Wiswell, Connor, and Howard, 1958; Henriksson, 1960), and such vascular changes alone could be sufficient to precipitate pancreatitis. Pancreatitis associated with familial hyperlipaemia could be due to thrombotic lesions within the pancreatic vessels.

If the theory of duodenal reflux is correct there are two important implications for treatment.

1 Sphincterotomy is contraindicated. This operation is based upon the false concept of obstruction, and is potentially dangerous. Pancreatitis following sphincterotomy has been reported by many surgeons (Blatherwick and Pattison, 1954; Thompson and Derrick, 1957; Telford, 1958) and this is a complication one might expect if reflux of duodenal contents causes pancreatitis. The reason why more harm has not come from the operation may well be that, in careful hands, the terminal part of the pancreatic duct with its muscle sphincter is not damaged.

2 For chronic relapsing pancreatitis the logical operation is ligation of both pancreatic ducts. This would result in atrophy of acini, preservation of the islets of Langerhans, and prevention of duodenal reflux. It has been used in 17 patients with recurrent pancreatitis with varying success (Howard and Jordan, 1960) but analysis of these cases revealed eight only in which both pancreatic ducts were tied, and of these six were improved, one unimproved, and one died from unrelated causes. It is worth noting that none of these patients developed pancreatitis in the immediate post-operative period. A more convincing demonstration of the fact that obstruction of the pancreatic duct has little to do with the aetiology of pancreatitis could hardly be devised.

This operation is worthy of further consideration in those cases of chronic relapsing pancreatitis with persistent abdominal pain and pancreatic calcification, bearing in mind the possible complication of 
peptic ulceration resulting from lack of alkaline pancreatic secretions (Elman and Hartmann, 1931). It would also allow safe biopsy of the outlet of the pancreatic duct and examination of this area for pathological changes in the mucosal 'valvules'.

\section{SUMMARY AND CONCLUSIONS}

Current theories about the pathogenesis of pancreatitis are unsatisfactory.

Active proteolytic enzymes present as a result of reflux of duodenal contents into the pancreatic ducts, will produce all the characteristic features of acute haemorrhagic pancreatitis.

The mechanical conditions under which 'duodenal reflux' occurs in man and in the experimental animal are described.

Reflux of duodenal contents as the cause of most cases of pancreatitis is wholly consistent with known facts about the disease.

The implications for treatment are briefly discussed.

I am indebted to Dr. H. A. Luke and Mr. G. Grove for the choledochogram and to Dr. David Race and Dr. T. E. Lowe for helpful criticism.

\section{REFERENCES}

Archibald, E. (1919). The experimental production of pancreatitis in animals as the result of the resistance of the common duct sphincter. Surg. Gynec. Obstet., 28, 529-545.

Bartlett, M. K., and Nardi, G. L. (1960). Treatment of recurrent pancreatitis by transduodenal sphincterotomy and exploration of the pancreatic duct. New Engl. J. Med., 262, 643-648.

Becker, V., and Schaefer, J. (1957). Die Bedeutung des Speichelödems für die Pankreasatrophie nach experimenteller Gangunterbindung. Virchows Arch. path. Anat., 330, 243-266.

Blatherwick, N. H., and Pattison, A. C. (1954). Acute pancreatitis complicating choledochal sphincterotomy. Amer. J. Surg., 88, 129-135.

Caroli, J., Porcher, P., Pequignot, G., and Delattre, M. (1960). Contribution of cineradiography to study of the function of the human biliary tract. Amer. J. dig. Dis., 5, 677-696.

Clark, E. (1942). Pancreatitis in acute and chronic alcoholism. Ibid., 9, 428-431.

Cross, K. R. (1956). Accessory pancreatic ducts: special reference to the intrapancreatic portion of the common duct. Arch. Path., 61, 434-440.

Dardinski, V. J. (1935). The anatomy of the major duodenal papilla of man, with special reference to its musculature. $J$. Anat. (Lond.), 69, 469-478.

Dragstedt, L. R., Haymond, H. E., and Ellis, J. C. (1934). Pathogenesis of acute pancreatitis. Arch. Surg., 28, 232-291.

Elman, R., and Hartmann, A. F. (1931). Spontaneous peptic ulcers of duodenum after continued loss of total pancreatic juice. Ibid., 23, 1030-1040.

Ferguson, J. H., Wilson, E. G., Iatridis, S. G., Rierson, H. A., and Johnston, B. R. (1960). Enzymes and blood clotting. I. Trypsin as an accessory factor. J. clin. Invest., 39, 1942-1952.

Ferrini, U., and Zito, R. (1961). Action of trypsin on Bence-Jones protein derivatives. Nature (Lond.), 189, 485.
Forell, M. M. (1962). Activation and inhibition of pancreatic proteolytic enzymes and their clinical significance. Germ. med. Mth. 7, 37-40.

Henriksson, C. (1960). Acute hyperparathyroidism and acute pancreatitis. Acta path. microbiol. scand., 50, $42-54$.

Hicken, N. F., and McAllister, A. J. (1952). Is the reflux of bile into the pancreatic ducts a normal or abnormal physiologic process? Amer. J. Surg., 83, 781-786.

Hosie, R. T., and Ziffren, S. E. (1956). The relationship of collagenase to pancreatitis. Surgery, 40, 185-190.

Howard, J. M., and Jordan, G. L. (1960). Surgical Diseases of the Pancreas, p. 234. Lippincott, Philadelphia.

Hueper, W. (1927). Metastatic calcifications in the organs of the dog after injections of parathyroid extract. Arch. Path., 3, 14-25.

Hughes, E. S. R., and Kernutt, R. H. (1954). The terminal portion of the common bile duct and of the pancreatic duct of Wirsung. Aust. N.Z. J. Surg., 23, 223-235.

Judd, E. S. (1921). Relation of the liver and the pancreas to infection of the gallbladder. J. Amer. med. Ass., 77, 197-201.

Mann, F. C., and Giordano, A. S. (1923). The bile factor in pancreatitis. Arch. Surg., 6, 1-30.

McCutcheon, A. D. (1962). Aetiological factors in pancreatitis. Lancet, 1, 710-712.

- - and Race, D. (1962). Experimental pancreatitis: A possible aetiology of postoperative pancreatitis. Ann. Surg., 155, 523-531.

- _ (1963). Experimental pancreatitis: Use of a new antiproteolytic substance, Trasylol. Ibid., 158, 233-239.

McJunkin, F. A., Tweedy, W. R., and Breuhaus, H. C. (1932). The parathyroid hormone. Arch. Path., 14, 649-659.

Newman, H. F., Weinberg, S. B., Newman, E. B., and Northup, J. D. (1958). The papilla of Vater and distal portions of the common bile duct and duct of Wirsung. Surg. Gynec. Obstet., 106, 687-694.

Opie, E. L. (1901). The etiology of acute haemorrhagic pancreatitis. Bull. Johns Hopk. Hosp., 12, 182-188.

- (1910). Disease of the Pancreas, its cause and nature, 2nd ed., p. 150. Lippincott, Philadelphia.

Perman, E. (1935). Surgical treatment of gastric and duodenal ulcer. Acta chir. scand., 77, suppl., 38, p. 142.

Pfeffer, R. B., Stasior, O., and Hinton, J. W. (1957). The clinical picture of the sequential development of acute hemorrhagic pancreatitis in the dog. Surg. Forum, 8, 248-251.

Probstein, J. G., and Blumenthal, H. T. (1961). Twenty-five years experience with pancreatitis. Amer. J. Gastroent., 35, 602-611.

Reid, L. C., Paulette, R. E., Challis, T. W., and Hinton, J. W. (1958). The mechanism of the pathogenesis of pancreatitis necrosis and the therapeutic effect of propythiouracil. Surgery, 43, 538-549.

Sc'iwegler, R. A., Jr. and Boyden, E. A. (1937). The development of the pars intestinalis of the common bile duct in the human fetus, with special reference to the origin of the ampulla of Vater and sphincter of Oddi. I. The involution of the Ampulla. Anat. Rec., 67, 441-467.

Sterling, J. A. (1949). The termination of the common bile duct. Rev. Gastroent., 16, 821-845.

Telford, D. (1958). Postoperative acute pancreatitis. Canad. J. Surg., 2, 22-28.

Thal, A. P., Perry, J. F., and Egner, W. (1957). A clinical and morphologic study of forty-two cases of fatal acute pancreatitis. Surg. Gynec. Obstet., 105, 191-202.

Thomas, W. C. Jr., Wiswell, J. G., Connor, T. B., and Howard, J. E. (1958). Hypercalcemic crisis due to hyperparathyroidism. Amer. J. Med., 24, 229-239.

Thompson, J. A., and Derrick, J. R. (1957). The diagnosis and management of acute pancreatitis. Amer. J. Surg., 94, 558-563.

Wallensten, S. (1958). Acute pancreatitis and hyperdiastasuria after partial gastrectomy. Acta chir. scand., 115, 182-188.

Wang, C. C., Wang, K. J., and Grossman, M. I. (1950). Effects of ligation of the pancreatic duct upon the action of secretin and pancreozymin in rabbits with a correlated histological study, Amer. J. Physiol., 160, 115-121.

White, T. T., and Magee, D. F. (1960). Perfusion of the dog pancreas with bile without production of pancreatitis. Ann. Surg., 151. 245-250. 